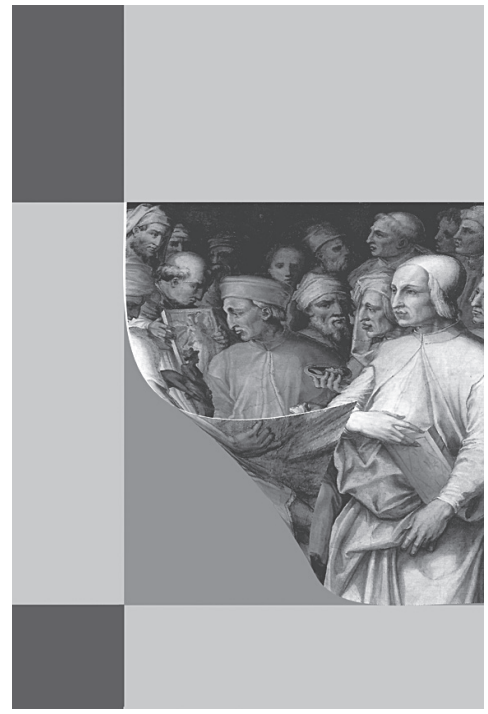




\title{
POSSÍVEIS SIGNIFICADOS DA PESQUISA NA PRÁTICA DOCENTE: IDEIAS PARA FOMENTAR O DEBATE*
}

\author{
Júlio Emílio Diniz-PereirA ${ }^{* *}$ \\ Mitsi Pinheiro de Lacerda ${ }^{* * *}$
}

\begin{abstract}
RESUMO: Com o propósito de fomentar o debate em universidades e escolas brasileiras, abordaremos, neste artigo, possíveis significados da pesquisa na prática docente. Trazemos para a discussão perguntas, tais como: quais os possíveis significados da pesquisa na prática docente? Quais as dificuldades e os desafios, em nosso país, para a realização da investigação na escola pelos próprios profissionais que lá trabalham? Qual a relevância desse tipo de pesquisa para a introdução de inovações no currículo escolar e para a formação docente? Ainda em termos da formação, não seria o enfoque na pesquisa mais uma escolha arbitrária que estaria negando outras possibilidades formativas também relevantes?
\end{abstract}

Palavras-chave: Pesquisa na prática docente. Formação docente. Currículo.

\section{POSSIBLE MEANINGS OF THE RESEARCH ON TEACHING PRACTICES: IDEAS TO CONTRIBUTE TO THE DEBATE}

ABSTRACT: Trying to stimulate the debate on "teachers as researchers" in Brazil, this article searches to discuss some possible meanings of this type of inquiry. It brings up to the debate some questions, such as: What are the possible meanings of "teachers

\footnotetext{
* A iniciativa de se escrever este artigo surgiu da participação conjunta dos autores em uma mesa-redonda sobre "Pesquisa na prática docente", realizada durante o IV Simpósio de Formação e Profissão Docente (SIMPOED), em Ouro Preto, no dia 6 de outubro de 2006.

** Doutor em Educação e professor adjunto da Faculdade de Educação da Universidade Federal de Minas Gerais (UFMG). E-mail: juliodiniz@fae.ufmg.br

*** Doutora em Educação e professora do Instituto do Noroeste Fluminense de Educação Superior, Universidade Federal Fluminense (UFF).E-mail: mitsipinheiro@yahoo.com.br
} 
as researchers?" What are the main difficulties and challenges in order for teachers to develop inquiry in their schools in Brazil? What is the relevance of this type of research in order to introduce innovations into the curriculum and teacher education? Speaking of teacher education, would not be the emphasis on research another arbitrary choice that might be neglecting other also relevant professional possibilities?

Key words: Teachers as researchers. Teacher education. Curriculum.

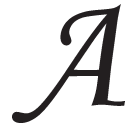

té princípios da década de 1980 , as pesquisas em docência e formação de professores no Brasil investigavam fundamentalmente sobre a prática docente, e isso configurava, na maioria dos casos, uma relação de distanciamento entre pesquisador e escola, fazendo com que esta fosse retratada a partir de um olhar externo. Empregando abordagens metodológicas que dialogavam com a intencionalidade de investigar sobre a escola, essas pesquisas educacionais produziam, muitas vezes, uma imagem negativa dessa escola, e, sobretudo, de professores e professoras. Isso conduzia a um distanciamento entre a produção acadêmica e a prática escolar, fazendo com que as pessoas que trabalham nas escolas não se interessassem pelos conhecimentos produzidos nas universidades, ao mesmo tempo em que dificultava aos próprios pesquisadores conhecer e investigar os interesses daqueles profissionais.

Pesquisar sobre a escola, sobre os professores, enfim, sobre o outro, era algo que não contribuía de forma significativa para o conhecimento do cotidiano escolar e para a necessária aproximação entre universidade e escola. Esse modelo de pesquisa começava a mostrar sua insuficiência. Já não bastava olhar para o outro, observar suas práticas e desenvolver análises sobre tudo isso. Era preciso repensar o lugar do pesquisador, questionar as abordagens metodológicas empregadas e, acima de tudo, abandonar qualquer tentativa de explicar as práticas para, diferente disso, tentar compreender os significados que as perpassavam.

Têm início, então, pesquisas na e com a escola. Os professores e as professoras, antes tomados na qualidade de meros "objetos", passam a ser vistos como sujeitos, participantes do processo de investigação. Preocupaçôes epistemológicas levam os pesquisadores a questionar 
o conhecimento que produzem, sua relevância e capacidade de contribuir com a escola por meio dos resultados de suas investigações. Assim, de objeto de pesquisa, a prática docente passa a ser compreendida como espaçotempo ${ }^{1}$ de formação e de investigação coletiva.

Neste artigo, trazemos para a discussão algumas questóes, tais como: quais os possíveis significados da pesquisa na prática docente? Quais as dificuldades e os desafios, em nosso país, para a realização da investigação na escola pelos próprios profissionais que lá trabalham? Qual a relevância desse tipo de pesquisa para a introdução de inovações no currículo escolar e para a formação docente? Ainda em termos da formação, se um dia enfatizamos o domínio dos conteúdos para depois nos concentrarmos no domínio dos métodos, não seria o enfoque na pesquisa mais uma escolha arbitrária que estaria negando outras possibilidades formativas também relevantes?

Dessa maneira, com a intenção de fomentar o debate sobre o tema, o que pretendemos abordar neste artigo é discutir possíveis significados da pesquisa na prática docente, e não o que ela de fato significa. É muito importante que destaquemos este nosso propósito uma vez que a problematização que traremos a seguir se refere às nossas preocupaçốes somente, e não se trata de questôes que tenhamos recebido de um coletivo de professores e professoras, até porque, enquanto estamos aqui pensando sobre este assunto, eles estão na escola tratando de outras coisas que demandam deles uma resposta muito mais imediata.

Mas, afinal, o que denominamos de pesquisa na prática docente?

O significado da palavra "pesquisa" é polissêmico - portanto, dependendo de quem a utiliza, e do contexto que a envolve, pode apresentar significados diferentes para pessoas diferentes. Tomemos, a princípio, a pesquisa como atividade científica desenvolvida no universo acadêmico. Não obstante as diversas orientações teóricas, metodológicas e epistemológicas, a pesquisa científica busca dialogar com o paradigma no qual se inscreve. Tradicionalmente, as pesquisas percorrem caminhos os quais as caracterizam como científicas, com a intencionalidade de conhecer determinado objeto para posteriormente socializar esse conhecimento. Como já nos ensinou Thomas Kuhn (2001), imersos em atividades de investigações acadêmicas, pesquisadores 
Possíveis significados da pesquisa na prática docente: ideias para fomentar o debate

e pesquisadoras utilizam uma linguagem comum aos membros da comunidade científica da qual participam, e que os distingue como tais.

O desenvolvimento de pesquisas na prática docente é algo ainda polêmico no meio acadêmico, especialmente entre aqueles que, abusando de uma linguagem prescritiva, apresentam e formulam as direções que os currículos escolares e a formação de professores devem seguir. Essa polêmica provavelmente não existiria caso se tratasse de algo a ser mantido sob o controle dessas mesmas pessoas, algo que pudesse ser administrado por elas - mas, daí perguntamos: quem pode controlar a produção de conhecimentos do outro? A polêmica no meio acadêmico acerca da possibilidade (ou não) de haver pesquisas na prática encontra-se relacionada a questóes de poder, e isso porque ainda há quem olhe para a pesquisa na prática como algo que possa competir com a pesquisa acadêmica, abalando sua legitimidade. ${ }^{2}$

Assim, podemos encontrar nas universidades quem defenda e quem critique, com bastante intensidade, o desenvolvimento da pesquisa na prática docente. Examinando o que dizem, podemos notar que ambos os grupos, embora discordem entre si, dispõem de concepções semelhantes acerca do que seria essa pesquisa. Grande parte dos acadêmicos envolvidos nessa discussão toma a pesquisa científica como modelo para a investigação na prática, e parece-nos que reside aí a razão de toda a discórdia, pois o que caracteriza a segunda é a simultaneidade entre trabalho e pesquisa - o que, para alguns acadêmicos, configura essa investigação como qualquer outra coisa que não a pesquisa científica. A investigação desenvolvida na prática dispõe, portanto, de um estatuto epistemológico e metodológico próprio e ainda pouco conhecido, e que em muito pouco se assemelha à pesquisa científica.

A pesquisa na prática docente trata-se de uma investigação desenvolvida no cotidiano escolar e compreendida como discussão permanente acerca do currículo, da prática e da problemática social. Trata-se ainda de uma pesquisa que possibilita a professores e professoras das escolas se firmarem na qualidade de sujeitos que autogerenciam sua própria formação, auxiliados pelo conhecimento teórico tomado como texto dialógico junto à tessitura do cotidiano escolar. Refere-se também a uma pesquisa que minimiza a tutela e legitima a emancipação docente, no sentido de romper com essa pretensiosa via de mão única 
em que a palavra externa historicamente vem tentando dizer o que deve ser a escola. Uma pesquisa que possibilita o conhecimento das teorias presentes nas práticas pedagógicas, as quais possam dialogar com o conhecimento teórico produzido fora da escola. Remete ainda a um trabalho que potencializa a atitude investigativa no cotidiano escolar e propicia a discussão acerca de uma epistemologia das classes populares, inserindo na prática a discussão permanente sobre as relações entre sociedade e escola. Por fim, significa também uma pesquisa que fortalece na escola o trabalho coletivo entre professores e professoras, levando-os a sistematizar o conhecimento que produzem.

A pesquisa na prática docente, desenvolvida por professores e professoras das escolas, é, além do mencionado anteriormente, uma forma bastante interessante e eficaz de desenvolvimento profissional (Zeichner \& Diniz-Pereira, 2005). É inegável a contribuição da pesquisa nos processos formativos, uma vez que a prática investigativa pressupõe a articulação de processos cognitivos, linguísticos, criativos, dialógicos e outros mais. A pesquisa, portanto, interfere positivamente na constituição dos saberes docentes e na compreensão de sua própria prática profissional. Favorece a tessitura de uma escola em que o conhecimento produzido passa a ser sistematizado, discutido, socializado - uma escola em que as proposições externas se misturam às proposiçóes internas.

Por fim, do ponto de vista político, a pesquisa na prática docente também pode ser vista como um movimento contra-hegemônico que contribui para a ruptura de uma determinada forma de saber e poder (Diniz-Pereira, 2002). Socializando os saberes oriundos da prática, e tomando a teoria como texto cuja serventia é a interlocução com esses saberes, a prática investigativa na escola favorece o esfacelamento de uma relação endurecida, onde tradicionalmente a teoria era tomada como texto a ser transformado em método e aplicado na prática.

Desenvolveremos um pouco mais, na seção seguinte, o tema da relação teoria e prática, procurando explicitar a necessidade de outra compreensão para que se aceite e se admita a legitimidade e a relevância da pesquisa na prática docente. Porém, como essa temática já tem sido bastante explorada na literatura especializada, não é nosso objetivo apresentar aqui uma discussão aprofundada sobre o assunto. 
Pesquisa na prática docente: necessidade de uma mudança de olhar sobre a relação teoria e prática

Como sabemos, tradicionalmente, espera-se que a teoria educacional seja aplicada de forma direta à prática docente. Nos programas de formação profissional e nas escolas, é bastante comum ouvirmos frases do tipo: "Conheça a teoria e aplique-a em sua sala de aula". E, então, dispomo-nos a conhecer a teoria, para depois descobrir que ela não se encaixa perfeitamente em nossas salas de aula. E isso acontece porque a primeira lição que nos ensina a teoria - e isso dificilmente aprendemos - é que ela só nos oferece serventia se a transformarmos em outra coisa: em conhecimento. Teoria alguma se aplica diretamente a prática alguma, mas toda teoria se entrega facilmente aos desdobramentos que alguém faz dela.

Desse modo, de acordo com a visão tradicional, a prática é concebida como ponto de chegada. A teoria, o método e, na atualidade, a pesquisa destinam-se e devem se aplicar à prática. Tudo isso deveria nos causar estranhamento, afinal o lugar de chegada remete-nos à idéia de ponto final, de terminalidade, e, em se tratando da teoria, do método e da pesquisa, a prática poderia ser entendida, então, apenas como campo de aplicabilidade. Essa relação linear em direção à prática desconsidera justamente duas de suas mais significativas características: o movimento e a imprevisibilidade. A prática docente, portanto, não pode ser considerada ponto de chegada, não pode ser considerada espaçotempo de aplicabilidade de qualquer coisa que seja, e isso porque a prática não é um lugar inerte onde algo possa ser simplesmente depositado.

É possível encontrar, na literatura educacional, no que diz respeito não somente às reformas curriculares, mas também aos programas de formação, muitas críticas a ações verticalizadas, ou seja, aquelas implementadas de cima para baixo. Essas açôes são pensadas em esferas que não a escola, mas que deveriam ser por ela executadas. Aparentemente, há aqueles que pensam e aqueles que executam e, se assim fosse, a implementação da pesquisa na prática docente seria algo simples de ser efetivado - bastaria um decreto e professores e professoras das escolas se tornariam pesquisadores na próxima segunda-feira. Isso, porém, não se passa assim. Se buscarmos nos estudos sobre currículo, por exemplo, poderíamos perceber a distância que há entre as diretrizes propostas por um poder central e o que efetivamente acontece nas 
escolas. Isso nos leva a desconfiar de que as pessoas produzem coisas, e Certeau (1994) já nos disse isso há tempos.

Proposições verticalizadas só existem na intenção de quem ocupa o lugar de poder e na crítica de quem procura desvendá-las, porque, nas escolas, as pessoas tomam essas proposiçóes e fazem outras coisas com elas. E se isso realmente acontece, é preciso então saber o que fazem, para, assim, podermos compreender como é possível a pesquisa na prática de quem trabalha na escola, o que, além de ser algo diferente da pesquisa científica, também é algo bastante diferente da investigação desenvolvida por alguém que se encontra no momento da formação inicial.

As implicações do desenvolvimento da pesquisa na prática docente para a formação de professores serão discutidas mais adiante neste texto. Antes, diante de todas as dificuldades enfrentadas pela educação formal no Brasil, não podemos de maneira alguma romantizar esse tema e, por isso mesmo, mencionaremos, a seguir, alguns desafios que a pesquisa na prática docente enfrenta em nosso país.

Desafios do desenvolvimento da pesquisa na prática docente no Brasil

Como se sabe, quem trabalha em escolas brasileiras - e, talvez, isso não seja muito diferente em vários outros lugares do mundo - envolve-se, na maior parte do tempo, apenas com atividades de ensino o que não garante, necessariamente, a aprendizagem efetiva e significativa entre os alunos. A carga horária dos docentes concentra-se nas salas de aula e pressupõe a elaboração de planejamentos, cumprimento de propostas curriculares, processos diferenciados de avaliação e todas as demais atividades relacionadas ao ensino. Além disso, quem trabalha na escola também precisa destinar uma parcela de seu tempo às reuniōes pedagógico-administrativas, em que, geralmente, as açôes limitam-se a questões técnicas e burocráticas. A formação continuada, desenvolvida a partir dos problemas que emergem da própria sala de aula, praticamente não existe.

Além disso, as condições desfavoráveis de trabalho dos nossos docentes - salários aviltantes, dupla ou até mesmo tripla jornada de trabalho, sobrecarga de aulas, número excessivo de alunos por sala de aula etc. -, na maioria das redes de ensino brasileiras, praticamente 
Possíveis significados da pesquisa na prática docente: ideias para fomentar o debate

inviabilizam a pesquisa na escola. Estamos bastante conscientes de que, mantidas essas condições, a pesquisa na escola poderia significar apenas a intensificação do trabalho docente. Assim, poderíamos perguntar: como desenvolver, na escola, ensino e pesquisa ao mesmo tempo?

Se tomarmos o modelo de pesquisa científica como norteador da investigação desenvolvida na prática docente, podemos afirmar que ensinar e pesquisar concomitantemente na escola é algo impossível. É preciso, pois, desvencilharmo-nos desse modelo de investigação e tentarmos, junto com professores e professoras de escolas, discutir possibilidades de inserção da pesquisa no ensino, ao mesmo tempo em que se lute para que as condiçóes de trabalho dos docentes melhorem significativamente. Para tal, precisamos pensar em uma investigação que não objetive perseguir os mesmos caminhos metodológicos da pesquisa científica, que contribua para transformar as práticas pedagógicas, registrar conhecimentos que vêm sendo produzidos, redimensionar a relação com a teoria e, finalmente, problematizar a relação entre sociedade e escola. Se a pesquisa científica parte de um problema delimitado no interior de um tema mais amplo, a pesquisa desenvolvida na prática docente é algo que não começa em um lugar predeterminado, mas que reside na complexidade da prática, na necessidade de compreender o cotidiano escolar, no desejo de compreender algo que venha causando indignação e surpresa. Como fazer isso, então?

Não há respostas simples para esta pergunta. Tampouco acreditamos que será por meio da apresentação de uma receita que as dificuldades e os desafios em relação ao desenvolvimento da pesquisa na prática docente serão resolvidos. Pensamos que o lugar para começar a buscar uma pluralidade de posicionamentos a respeito desse assunto e disso não temos dúvidas - é a própria escola. Se a pesquisa tem o potencial para transformar a escola em um lugar melhor - do ponto de vista intelectual, humano e da aprendizagem (mais do que do ensino propriamente) - e se os professores e as professoras devem investigar suas próprias práticas para que isso aconteça, então é imperativo que sejam inseridos na discussão dessa proposição os que têm sido incluídos apenas como executores. Se a professores e professoras continuar sendo relegado o lugar de executores de ideias pensadas por outros, essas proposições muito dificilmente farão parte da tessitura escolar e continuarão sendo um apêndice - não importa o quanto essas ideias sejam coerentes e interessantes. 


\section{Implicações para a formação docente}

Sabemos, por meio da literatura especializada e pelas práticas que ainda se perpetuam em muitas instituiçōes de ensino superior no país, que um dia a formação de professores se preocupou enormemente com o domínio dos conteúdos, e, assim, professores e professoras concluíam sua formação inicial supostamente dominando os conteúdos das disciplinas que iriam ministrar. Isso, contudo, foi mostrando sua insuficiência, e, assim, também os programas de formação profissional, baseados no modelo da racionalidade técnica, em que o conteúdo, desprovido dos meios, não respondia às necessidades educativas.

Minimizando os conteúdos e intensificando os métodos e as técnicas, os programas de formação promoveram uma mudança significativa, mas quase nenhuma transformação. Aqueles e aquelas que estavam sendo formados continuavam sendo vistos como alguém que precisava conhecer algo e que, para conhecer, precisava dominar esse algo conhecido. Esse conhecimento, contudo, estava fora do sujeito conhecedor, não era produzido por ele e tampouco se originava a partir da prática. Substituindo a ênfase nos conteúdos pela ênfase nos métodos, houve mudança de enfoque, mas a professores e professoras coube manter-se no extremo de um processo verticalizado, no lugar de quem recebe, e por isso afirmamos que se tratou somente de uma mudança, não de uma transformação.

Não queremos com isso afirmar que os programas de formação devam relegar a segundo plano o ensino dos conteúdos a serem ministrados, nem que também não devam problematizar os métodos utilizados. Qualquer atividade de ensino precisa estar articulada, necessariamente, a um currículo, a uma teoria, a um método, mas, se quisermos uma transformação e não somente uma mudança, é preciso que as atividades de ensino estejam articuladas a currículos, teorias e métodos que sejam problematizados permanentemente por aqueles e aquelas que trabalham nas escolas, por quem os precisa articular, compreender, refutar e inventar cotidianamente em meio às práticas pedagógicas.

No modelo atual, em se tratando da pesquisa na prática docente, quando esta se refere à investigação como eixo formativo dos cursos de licenciatura, podemos notar grande semelhança com o que se faz na pesquisa científica: os alunos e alunas das licenciaturas delimitam um objeto, fazem uma revisão de literatura sobre o tema, detalham a 
Possíveis significados da pesquisa na prática docente: ideias para fomentar o debate

metodologia de pesquisa, coletam e analisam dados para, por fim, produzirem um trabalho de conclusão de curso - geralmente chamado de monografia - que é considerado um dos pré-requisitos da habilitação. Embora não desconsideremos a relevância de todo esse trabalho de iniciação científica, pensamos que ainda precisamos avançar na discussão acerca da formação do professor e da professora pesquisadores tendo como atividade formativa o desenvolvimento de uma monografia. ${ }^{3}$ Mas esta é uma outra questão, que não pretendemos abordar neste artigo.

Simplesmente inserir a dimensão da pesquisa nos cursos de licenciatura não garante, porém, a formação do professor e da professora na qualidade de pesquisadores, e, mesmo que isso fosse possível, o estatuto epistemológico e metodológico empregado na investigação desenvolvida durante a formação inicial muito dificilmente poderia ser utilizado em meio à prática pedagógica desenvolvida no cotidiano escolar. Pensamos que a inserção da dimensão da pesquisa nos cursos de licenciatura em muito tem ajudado a desconstruir a artificialidade que havia na parte prática desses cursos, mas em pouco tem auxiliado para a compreensão de como isso poderia dar-se no chão da escola.

Se a pesquisa na prática docente, tomada como eixo articulador dos cursos de licenciatura, em diálogo com o estágio e a prática de ensino, pode re-significar as disciplinas de conteúdo, também a pesquisa na prática docente, desenvolvida por professores e professoras das escolas, pode imprimir movimento ao conhecimento teórico que, tradicionalmente, vem sendo tomado com a intenção de ser aplicável. Cabe aqui, então, formular outra questão que deixamos para o debate: se não pretendemos minimizar o acesso à teoria intensificando a investigação sobre a prática, como poderemos estabelecer uma relação dialógica entre ambas?

Por fim, acreditamos que o movimento de pesquisa na prática docente pode influenciar os cursos de licenciatura, minimizando o enfoque anteriormente oferecido aos conteúdos e aos métodos, e inserindo a pesquisa como eixo articulador da formação. As exigências legais pela distribuição da parte prática no decorrer dos cursos, bem como a articulação entre a pesquisa, o estágio e a prática de ensino, também contribuem para que, na atualidade, a pesquisa seja tomada como importante componente dos programas de formação de professores. ${ }^{4}$ Quais interpretações estão sendo realizadas, nas universidades e 
demais instituições de ensino superior, sobre esse princípio norteador? Como tais interpretaçôes estão sendo traduzidas em termos de propostas curriculares para os cursos de formação inicial de professores nas diversas instituições de ensino superior brasileiras? Estas são questões também urgentes de serem pesquisadas e debatidas em nosso país.

\section{Considerações finais}

Os estudos acerca da docência e seus desdobramentos em proposições diversas avançaram bastante nas últimas décadas. Embora grande parte desses estudos tenha se restringido à universidade, defendemos a ideia de que a discussão atual - a pesquisa na prática docente é algo que precisa acontecer nas escolas. Caso contrário, perderá seu potencial de transformação para se esvaziar em discursos que ignoram que o desenvolvimento de pesquisas na prática é algo que já acontece na escola, independente e anteriormente ao discurso acadêmico. ${ }^{5}$

É preciso repensar as diferentes concepções de pesquisa, repensar o que compreendemos como prática e nos distanciarmos da tentativa de aproximar a pesquisa na prática do modelo da investigação científica. Mas, para isso, precisamos tomar como princípio que a prática é locus de produção de conhecimentos e que esses conhecimentos não concorrem à hegemonia e sim à legitimidade. São conhecimentos que dispõem de outra natureza, uma vez que não se configuram como teorias explicativas de algo, e sim como diálogo travado junto com os eventos que vão sendo tecidos no cotidiano escolar; são conhecimentos produzidos na prática e provocados por ela. Repensar as diferentes concepções de pesquisa é algo que convida ao debate acerca da legitimidade da pesquisa na prática, levando-nos a desvelar relações de poder que tacitamente informam posicionamentos contrários a essa prática.

Acrescido a esse debate, é importante conhecermos como as pesquisas são desenvolvidas por quem dispõe de um campo de investigação que é, ao mesmo tempo, seu campo de trabalho. Precisamos conhecer como essas pesquisas são realizadas, em detrimento de tentarmos regular sua natureza por meio de metodologias que não dialogam com elas (Lacerda, 2002). Precisamos compreender os diferentes processos por 
meio dos quais as pesquisas na prática são desenvolvidas sem focar tanto em seus produtos, comparando-os com os das universidades.

Como serão desenvolvidas as pesquisas na prática docente, então? Isso realmente não sabemos, e ficamos satisfeitos por não saber, pois, como disse a escritora Adriana Falcão, certeza é quando a ideia desiste e para. Concordando com ela, diríamos também que certeza é quando resolvemos sozinhos como são as coisas. Que certeza é quando parte de mim o que o outro deve ser e fazer. E que certeza é quando eu legitimo algo e nego o resto. Que possamos afirmar menos nossas certezas, portanto, e nos aproximar e conversar, universidade e escola, para, quem sabe, compreendermos, todos juntos, os significados da pesquisa na prática docente.

\section{Recebido em junho de 2007 e aprovado em abril de 2008.}

\section{Notas}

1. O termo "espaçotempo" é empregado aqui no sentido que lhe atribui Alves (2002), "para contrapor-se às [práticas] que, criadas na modernidade, nos obrigam à dicotomização da realidade".

2. Em trabalho apresentado no XIII ENDIPE, em Recife, um dos autores deste texto defende a ideia de que a "pesquisa sobre a formação docente" e a "pesquisa na formação docente" são atividades distintas que trazem contribuições específicas para a formação de professores, não devendo, pois, serem entendidas de uma maneira dicotômica, hierárquica e/ou como concorrentes (Diniz-Pereira, 2006).

3. É importante mencionar que um dos autores deste artigo, desempenhando sua função de formador de educadores, lecionando em cursos de licenciatura, adota o portfólio como trabalho de conclusão de curso e alternativa à monografia. Este tem demonstrado ser um poderoso instrumento para reflexão da prática e investigação das ações cotidianas na escola. A literatura especializada também atesta o poder do portfólio para a formação de professores e o desenvolvimento da pesquisa na prática docente (ver, por exemplo, Zeichner \& Wray, 2001).

4. Como se sabe, o documento das "Diretrizes Curriculares Nacionais para a Formação de Professores da Educação Básica, em nível superior”, enfatiza a pesquisa como elemento essencial na formação profissional do professor (Brasil, 2001). Parece-nos que as mais diversas interpretaçōes têm sido dadas a este princípio de formação e, por via de consequência, as mais diferentes formulações curriculares têm sido apresentadas para o cumprimento desse preceito legal.

5. Podemos referir, como exemplo, o que vem acontecendo no estado do Rio Grande do Sul, onde, desde 2000, professores e professoras apresentam e discutem resultados de pesquisas desenvolvidas em suas salas de aula durante o "Encontro sobre Investigação na Escola”, em parceria com as universidades locais. 


\section{Referências}

ALVES, N. Decifrando o pergaminho - o cotidiano das escolas nas lógicas das redes cotidianas. In: Oliveira, I.B.; Alves, N. (Org.). Pesquisa noldo cotidiano das escolas. Sobre redes de saberes. Rio de Janeiro: DP\&A, 2002.

BRASIL. Conselho Nacional de Educação. Parecer CNE/CP n. 009/ 2001. Diretrizes Curriculares Nacionais para a Formação de Professores da Educação Básica, em nivel superior, curso de licenciatura, de graduação plena. Brasília, DF, 8 de maio de 2001.

CERTEAU, M. A invenção do cotidiano. Artes de fazer. Petrópolis: Vozes, 1994.

DINIZ-PEREIRA, J.E. O movimento dos educadores-pesquisadores como estratégia para construção de modelos críticos e emancipatórios de formação docente. In: Diniz-Pereira, J.E.; Zeichner, K. (Org.). A pesquisa na formação e no trabalho docente. Belo Horizonte: Autêntica, 2002. p. 11-42.

DINIZ-PEREIRA, J.E.; ZEICHNER, K. (Org.). A pesquisa na formação e no trabalho docente. Belo Horizonte: Autêntica, 2002.

DINIZ-PEREIRA, J.E. "Pesquisas sobre formação docente" vs. "pesquisas na formação docente": diferenças teórico-metodológicas e conceituais. Encontro Nacional de Didática e Prática de Ensino, 13, Anais..., Recife: UFPE, 2006. (Publicação eletrônica em CD-ROM).

FALCÃO, A. Mania de explicação. São Paulo: Moderna, 2001.

KUHN, T.S. A estrutura das revoluçōes científicas. São Paulo: Perspectiva, 2001 .

LACERDA, M.P. Quando falam as professoras alfabetizadoras. Rio de Janeiro: DP\&A, 2002.

ZEICHNER, K.; DINIZ-PEREIRA, J.E. A pesquisa dos educadores e a formação docente voltada para a transformação social. Cadernos de Pesquisa, São Paulo, v. 35, n. 125, p. 63-80, 2005. 
Possíveis significados da pesquisa na prática docente: ideias para fomentar o debate

ZEICHNER, K.; WRAY, S. The teaching portfolio in US Teacher Education Programs: what we know and what we need to know. Teaching and Teacher Education, v. 17, n. 5, p. 613-621, 2001. 